\section{The effects of chronic maternal absorption of nicotine or hypoxic episodes upon the life span of the offspring*}

\author{
JOAN C. MARTIN† and R. F. BECKER** †† \\ Duke University Medical School, Durham, N.C. 27706
}

The offspring of rats subjected to either chronic hypoxic episodes $(\mathrm{H})$ or injections of $3.0 \mathrm{mg} / \mathrm{kg}$ of nicotine twice daily throughout pregnancy $(\mathrm{N})$ or injected throughout pregnancy and the nursing period $(\mathrm{N}-\mathrm{N})$ had significantly shorter life spans than did control offspring (S) of dams injected with a similar amount of isotonic saline twice daily. $\mathrm{H}$ animals died earliest, followed by $\mathrm{N}-\mathrm{N}$, $\mathrm{N}$, and $\mathrm{S}$ rats. These results paralleled those found in our previous studies which involved the use of reinforcement schedules, discrimination problems, and performance in activity wheels. In the latter case, group performance levels increased in the order of $\mathrm{H}, \mathrm{N}-\mathrm{N}, \mathrm{N}$, and $\mathrm{S}$. Tentative explanatory hypotheses for these differences among offspring groups include undernutrition in utero and maternal neglect following birth.

For the past 3 years, this laboratory has been engaged in the study of the physiological, morphological, and behavioral effects on rat offspring of mothers chronically stressed during the gestation period.

In previous behavioral studies, we determined that such hypoxic offspring $(\mathrm{H})$ and offspring whose dams received nicotine injections throughout gestation and the nursing period $(\mathrm{N}-\mathrm{N})$ were significantly lighter in weight at adulthood than were controls. They were also more active in the activity wheel than offspring (S) whose dams received saline injections during the same period (Martin \& Becker, 1970).

Utilizing the same treatments with a different group of rats, it was found that the same two groups ( $\mathrm{H}$ and $\mathrm{N}-\mathrm{N}$ ) performed less well on certain reinforcement schedules and made more errors on simple discrimination problems (Martin \& Becker, 1971) than did saline controls. In both instances, another group of offspring $(\mathrm{N})$, which had received nicotine indirectly only during gestation, did not perform significantly differently from controls.

*This research was supported in part by a grant from the American Medical Association (Project for Research on Tobacco and Health), and in part by NICHHD Grant No. 5 T01-HD-00164.

tReprints may be obtained from the first author: Department of Psychiatry, University of Washington Medical School, Seattle, Washington 98105.

**Now at Michigan State University, Department of Biomechanics, East Fee Hall, East Lansing, Mich. 48823.

t+The authors wish to thank Dr. Kallianos and the Liggett and Myers Research Laboratories, Durham, N.C., for redistilling the nicotine used in these studies.
The purpose of the following study was to determine whether these treatments would have a differential effect upon the life span of the rat offspring.

\section{PREGNANCIES}

Virgin Sprague-Dawley females bred in our laboratory from a colony originally obtained from Holtzman were mated overnight at 120 days of age. Ss were assigned to one of four groups, and treatment was begun the next day if sperm was present in the vaginal lavage.

TREATMENT
Gravid nicotine rats received $3.0 \mathrm{mg} / \mathrm{kg}$ of Eastman Kodak reagent-quality pure nicotine in a saline buffer injected subcutaneously in the abdominal skin twice daily for 21 days. For the purpose of injection, weight was determined on Day 1 of pregnancy.

The nicotine-nursing group received the same treatment, but with the drug continued through Postnatal Day 21. A 48-h postnatal recovery period was allowed before injections were resumed after delivery.

The saline animals received saline buffer twice daily throughout gestation.

It had been observed in our laboratory that nicotine administration to the pregnant guinea pig caused blanching and constriction of the uterine blood vessels. In an attempt to control for the possibility that the results of nicotine injections might be attributed to the decreased availability of oxygen to the fetus, a hypoxic group was added. Gravid rats were placed in an airtight Lucite chamber connected to a nitrogen and oxygen supply. The oxygen level was dropped to $4 \%$ during a period of $3.0 \mathrm{mg} / \mathrm{kg}$ of the $0.9 \%$ solution of
37.41 min. The Ss were kept at this level for an additional $5 \mathrm{~min}$ before being removed from the chamber. This procedure was repeated once a day through Day 21 of gestation. All animals were allowed to deliver normally.

\section{OFFSPRING}

These were littermates of the animals described in the previous activity study. The neonates were weaned at 21 days of age and females were discarded. Males were segregated according to treatment and placed three to four in a $17.5 \times 40.0 \mathrm{~cm}$ cage. They were provided with Purina Rat Chow ad lib and Neoterramycin was added daily to the drinking water. Each group numbered 10, except for the $\mathrm{H}$ and $\mathrm{N}-\mathrm{N}$ groups. Shortly after the experiment had begun, 2 from the $\mathrm{H}$ group were found to be female and had to be discarded; also, $1 \mathrm{~N}-\mathrm{N}$ rat escaped. Cagemates remained together until only one animal was left alive, at which time the survivor was placed in a smaller cage in order to conserve on rack space. The rats were never disturbed except to renew tail markings once a month.

\section{PROCEDURE}

Cages were checked twice daily for deaths on weekdays and once daily on weekends. Longevity was recorded in weeks and days. No autopsies were performed since the Veterinary Medicine Department was in the process of moving to new quarters during part of this period and their services were not available.

\section{RESULTS}

The $\mathrm{H}$ offspring died soonest, followed by the $\mathrm{N}-\mathrm{N}, \mathrm{N}$, and, lastly, the $S$ control offspring. Almost one-third of the control animals $(\mathrm{N}=3)$ were still alive when the experiment had to be terminated due to a laboratory transfer. None of the treated offspring were alive at that time.

Intragroup life span differences were extreme so that homogeneity of variance could not be assumed. The nonparametric Kruskal-Wallis rank statistic yielded an $\mathrm{H}=10.00$, df $=3$, $\mathrm{p}<.025$. The control group was then paired with each of the other treatments, and the Wilcoxon rank statistic was performed on each pairing, with the following results: $S$ vs $\mathrm{H}$ test, $\mathrm{p}<.01 ; \mathrm{S}$ vs $\mathrm{N}-\mathrm{N}, \mathrm{p}=.04 ; \mathrm{S}$ vs $\mathrm{N}, \mathrm{p}=.15$. The $\mathrm{LD} / 50$ point was reached at 54 weeks in the $\mathrm{N}-\mathrm{N}$ and $\mathrm{H}$ groups, at 67 weeks in the $\mathrm{N}$ rats, and at 69 weeks in the $S$ controls (see Fig. 1).

DISCUSSION
The results paralleled behavioral trends noted earlier with similarly treated animals. As cited previously, the activity level of littermates in the behavioral study went from most to 


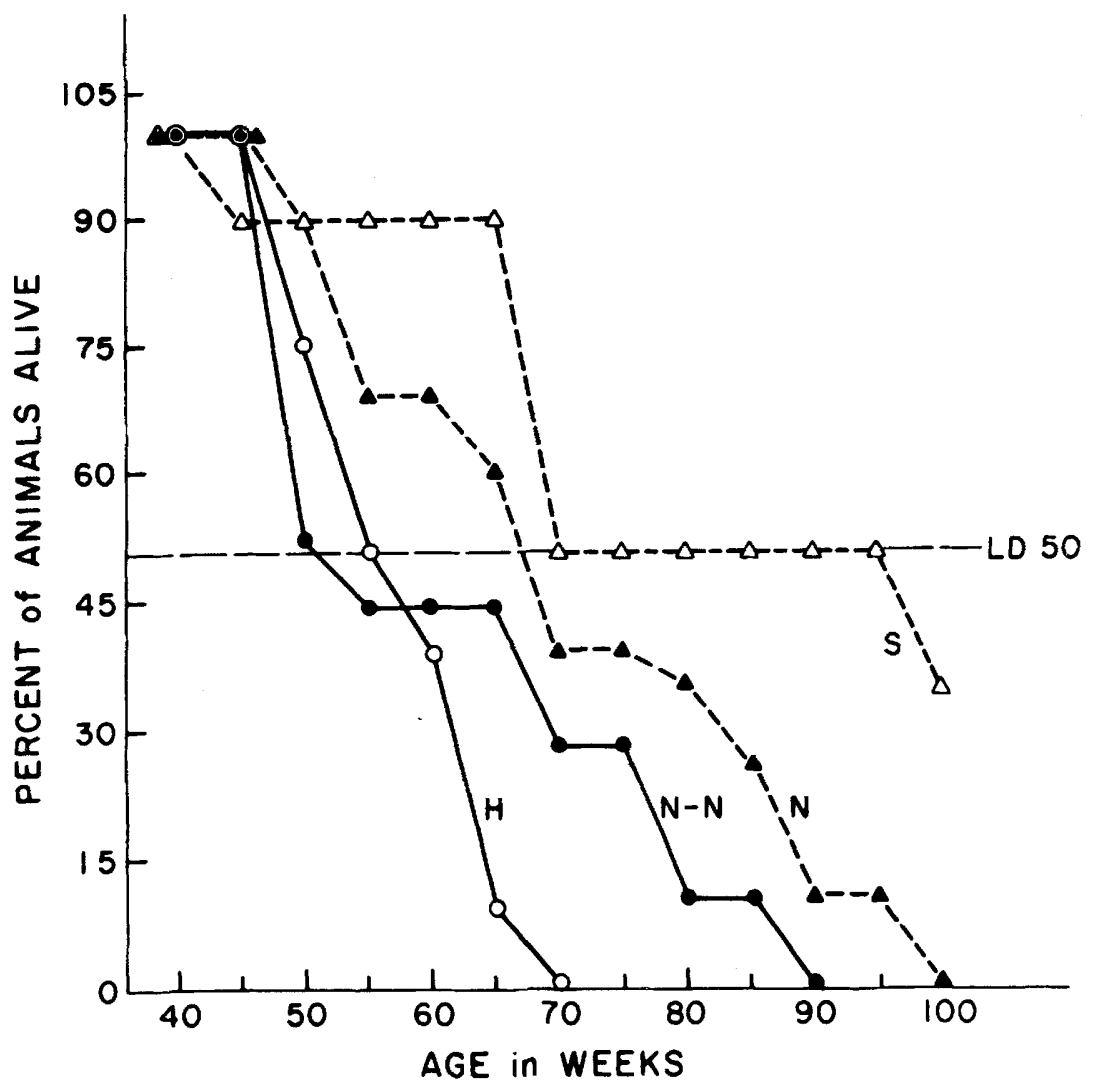

Fig. 1. Longevity among the young in each study group. The $H$ group consisted of offspring whose dams received hypoxic episodes during the gestational period; the dams of the $\mathrm{N}$ group received nicotine injections twice daily during gestation; the dams of the $N-N$ group received ricotine injections twice daily during gestation and the nursing period; the $S$ dams received saline injections twice daily during the gestational period. The LD/50 line marks the point at which $50 \%$ of the animals within a group were dead.

least active in the following order: $\mathrm{N}$, $\mathrm{N}-\mathrm{N}, \mathrm{N}$, and $\mathrm{S}$.

An anatomical-physiological study performed in this laboratory (Becker \& Martin, 1971), which replicated the treatments described above but with four minor variations, found that gravid $\mathrm{N}$ or $\mathrm{N}-\mathrm{N}$ rats delivered fewer young and that they were lighter in the mechanisms involved which might account for the differential life spans. Prenatal trauma has been implicated in a wide variety of postnatal behavioral differences (Vincent, 1958; Furchtgott \& Echols, 1958; Becker \& Donnell, 1952). We have found nothing in the literature which has related longevity to fetal treatment. Whether the shortened life spans are due to the treatments per se, some undernutrition in utero as a consequence of treatment, maternal neglect following birth, or a combination of these or other factors is unknown to us at the present time.

Life span studies are time-consuming and expensive, but this may prove to be an area with far-reaching consequences if the effects of fetal trauma prove replicable across species. It is hoped that investigators working with such species will gather additional information on the effects of treatment upon life span.

\section{REFERENCES}

BECKER, R. F., \& DONNELL, W. Learning behavior in guinea pigs subjected to asphyxia at birth. Journal of Comparative \& Physiological Psychology, 1952, 45, 153-162.

BECKER, R. F., \& MARTIN, J. C. Vital effects of chronic nicotine absorption and chronic hypoxic stress during pregnancy and the nursing period. American Journal of Obstetrics \& Gynecology, 1971.110, 522-533.

FURCHTGOTT, E. , \& ECHOLS, M. Activity and emotionality in pre- and neo-natally $X$-irradiated rats. Journal of Comparative \& Physiological Psychology, $1958,51,541-545$.

MARTIN, J. C., \& BECKER, R. F. The effects of nicotine administration in utero upon activity in the rat. Psychonomic Science, 1970, 19, 59-60.

MARTIN, J. C., \& BECKER, R, F. The effects of maternal nicotine absorption or hypoxic episodes upon appetitive behavior in rat of fspring. Developmental Psychobiology, 1971, 4, 133-147.

VINCENT, N. M. The effects of prenatal alcoholism upon motivation, emotionality, and learning in the rat. American Psychologist, 1958, 13, 401. 